\title{
Globally branded E-Government
}

\author{
Alptekin Erkollar ${ }^{1}$ and Birgit J. Oberer ${ }^{2}$ \\ ${ }^{1}$ ETCOP Austria, Austria \\ ${ }^{2}$ Kadir Has University, Kadir Has Caddesi Cibali, Istanbul
}

\begin{abstract}
E-government covers all government measures which use electronic media at the federal, state, and local government levels to provide qualitative improvements in the citizen's various spheres of life, optimization of business processes within the administration, and improvement of public image within an international competitive environment. Online electronic services that are made available by government to its interaction partners (citizens, businesses, or government authorities) are one piece of evidence for the changes that have occurred in the public sector. To meet the requirement to compete in an increasing area of globalization and to be competitive in global markets, public authorities must think about how to make their services more attractive compared with competitors. One aspect of becoming more competitive and differentiating oneself from competitors in the market is investing in global branding for e-government strategies. This paper presents an implementation guide for e-government strategies.
\end{abstract}

Keywords: E-Government, branding, public authority

\section{Introduction}

According to Erkollar and Oberer (2003) the influences of information technology are reshaping today's world. Information technology influences how organizations develop. Governments are given new tasks to fulfill and new possibilities to support their fulfillment efforts. Worldwide e-applications are the basis for establishing E-government services. On the local, national, and international stages, all global communication initiatives and e-government services provided to the government's stakeholders need to be branded. After a short overview of general electronic government services offered by public authorities, the authors emphasize the importance of globally branded communication for governments and their authorities and show how governmental authorities and governments can design and implement globally branded e-government strategies.

\section{Electronic Government Services (e-government)}

For Oberer (2002) E-government, meaning services by the government and its authorities provided online, has the potential to improve the relationship between administration, citizens, and business and includes all administrative measures at all levels. According to Wounger (2003) potential advantages accrued through e-government are: lower service delivery costs; enhanced knowledge sharing and collaboration; improved internal decision-making; increased public accountability and meeting citizen expectations for greater information access and increased citizen satisfaction levels.

Copyright (C) 2010 Alptekin Erkollar and Birgit J. Oberer. This is an open access article distributed under theCreative Commons Attribution License unported 3.0, which permits unrestricted use, distribution, andreproduction in any medium, provided that original work is properly cited. Contact author Alptekin Erkollar, email: erkollar@etcop.com 


\section{Government Communication}

Communication is an important function of government. Melichar (2007) mentioned that communication is jointly responsible for improving three principal elements of government:

- Accountability: explaining government stewardship and providing mechanisms to hold governments accountable;

- Effectiveness: building broad support and legitimacy for programs;

- Responsiveness: knowing citizens' needs and responding to them

Functions and ethical dimensions

Erkollar (2008) mentioned that the main functions of government communication are informing, engaging partners, and advocating, as well as persuading stakeholders to support policies and reforms. Enhanced citizen participation is one key indicator of the effectiveness of government communication, but many countries do not provide much information to citizens and do not enable citizen participation at all or only in an insufficient way. Neglecting or mishandling information provision to the public erects barriers to good governance. Undervaluing the benefits of improved government communication has a substantial multiplier effect. External communication (to the public and the media) can have a high impact on policy effectiveness and can help coordinate communication within governments. Consistent internal information is required to communicate effectively and efficiently with external audiences like the media or the public. Government communication should involve the provision of customer-oriented services and should build the capacity for citizens to provide government with feedback about the services provided. Government communication also has ethical dimensions. Governments need to be made aware of incentives to communicate because they often do not realize that communication is fundamental to their functioning. They have to be persuaded of the contribution of government communication to improved governance and development outcomes. According to Oberer (2008) ethical dimensions of government communication include:

- Providing information to constituents;

- Generating knowledge by listening to citizens and other stakeholders;

- Providing professional communication structures and methods;

- Supporting public discussion;

- Explaining the rights of citizens and working policies

Moreover, various access media for different countries and different stakeholders must be considered. Interface structures must be designed and implemented, and it must be determined whether a standard application can cover all requirements or a customized one is needed (demand and communication depend on different functions). To provide information to stakeholders effectively, two conditions have to be met: that the government has developed a culture of disclosure needs, and that it possesses the relevant information which is needed for the various communication channels.

Communication capacity and the communication environment

Erkollar (2008) mentioned that government communication ought to be more than a basic tool for crisis management. It should involve, among other things, a consulting role for policymakers, raising awareness, changing behavior, achieving consensus, supporting civic education, and a general transparency which involves listening to society's attitudes and to changes in values, traditions, and overall behavior. Sometimes governments lack qualified communication staff. There may not be a well-defined structure for communication, and there may be a lack of knowledge of how to generate government knowledge, how to identify relevant stakeholders, how to provide 
information to them, and how to communicate with them. Communication means both providing information and creating the possibility for the addressee to reply to the government messages. Much of the work in improving government communication involves addressing structural issues. A clear understanding of the substance of government policies is necessary. Melichar (2007) mentioned that for governments, it is also necessary to understand the key factors and basic rules of journalism.

Transaction procedures between governments and citizens

Currently, many governments do not even have the capacity to fulfill the task of oneway communication (information provision) effectively because of a lack of well-defined communication structures. Nevertheless, one-way communication is not enough to produce high-quality governance outcomes. Two-way communication between government and its stakeholders is needed to produce high-quality governance products. The better the two-way communication structures, the better will be the quality and sustainability of the governmental output. It is not enough for a government to communicate with the public about elections or politically risky issues. Governments need to be made aware that a lack of communication with its stakeholders gives opposing forces the possibility to dominate the public. A clear structure for different patterns of communication, as shown in Table 1 , is needed.

Table 1: patterns of communication

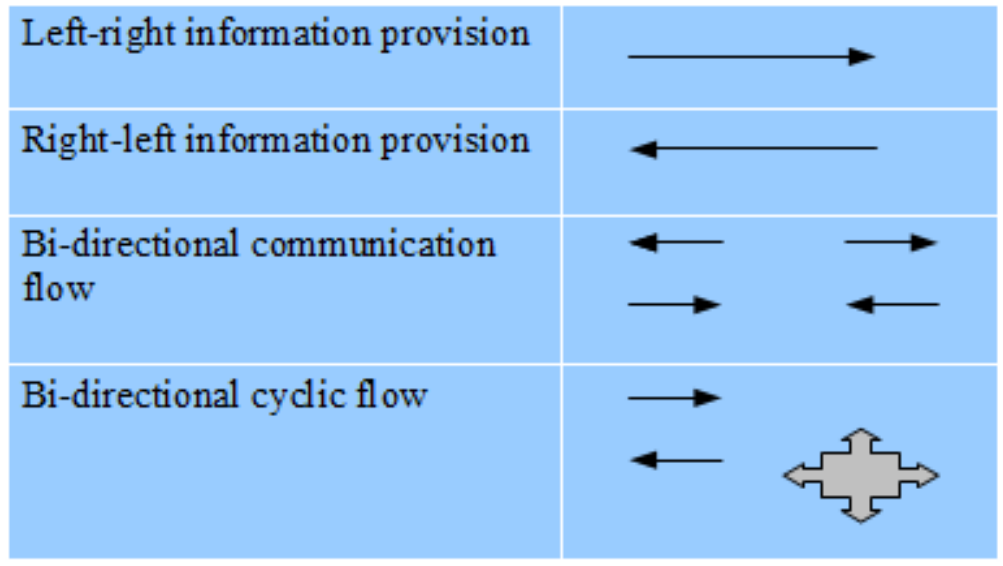

In addition, according to Erkollar and Oberer (2004) the 7C factors for the structure of web interfaces have to be considered.

\section{Government Branding}

Lakeworth (2008) mentioned that the American Marketing Association defines a brand as a "name, term, sign, symbol, or design, or a combination of them, intended to identify the goods and services of one seller or group of sellers and to differentiate them from those of other sellers". Branding can be defined as an output-generating process. The outputs are a brand and a brand identity for differentiating products, services, and corporations in an attractive and compelling way. Brands are critical marketing and communication assets. It is important to invest time in researching, defining, and building a brand. Clear and consistent brand messages encourage interest from an organization's stakeholders. 
According to Huntington (2007) many government agencies have adopted names and logos to give them a unique character and style. This creates the impression that the agency is energetic and forward-looking, which creates a positive impression for the agency's stakeholders. However, the other side of the coin is that this unique style can create an impression that the department is not part of the government, and its stakeholders, mainly the public, can become confused. Generally, an overall logo should be designed which presents a single recognizable brand for the government, making it easier for its stakeholders to recognize the government's products, entities, and services and to distinguish them from other levels of government and from the private sector as well. A global brand is a brand name of a product, service, or bundle of these with worldwide recognition. It provides the advantage of economies of scale in terms of interest generation and recognition. Although the product, service, or bundle and the brand itself remain the same worldwide, marketing and stakeholder communications have to consider local markets and their conditions and limitations, and the resulting marketing and communication strategies have to be tailored accordingly. Global branding is the process of generating and implementing a global brand and includes control structures as well as feedback loops.

\section{Guidelines for global government branding}

To define a brand, governments must be aware of various circumstances and conditions regarding their services, products, "customers," and internal operations. Lakeworth (2008) mentioned that the following questions must be answered as a basis for defining the brand:

- Which products and services are offered, and what is their quality?

- What are the core values of the government and its authorities?
- What messages does the organization want to send to its stakeholders?

- What is the structure of the target markets (local, regional, national, international)?

- Which characteristics of the government's services are attractive to the target markets?

- What is the specific profile of the government and its authorities?

The purpose of this discussion is according to Erkollar and Oberer (2004) to provide guidance to government agencies and other organizations regarding branding for internal and external communication, with reference to the 7C factors (comprehensiveness, current information, client orientation, clarity, courtesy, compatibility, and crosslinking) which are commonly used as a standard for web design. The objectives of a branding campaign are to increase the efficiency and effectiveness of government branding and the stakeholders' awareness of government programs, products, services, and policies. Lakeworth (2008) mentioned that all government agencies must use the government brand as their primary brand for external communication. An approved agency logo can be used as a secondary brand. Where the brand would be inappropriate because of size, the name of the government should be written. Oberer (2002) argues that for the successful implementation of branded egovernment strategies, a general set of critical conditions has been developed: The demand for electronic government services has been proved empirically. The main interest of the user of government services is simple and fast information access and transactions to simplify their interactions with government authorities. The use of electronic administrative services should therefore be demand- and impact-oriented. Oberer (2002) and Erkollar and Oberer (2004) mentioned that organizational, legal and technological conditions are:

- Redesign of administrative processes and structures: the premise is that the development 
of e-government and the redesign of administrative processes and structures must be harmonized and synchronized.

- Coordination of organizational and technological redesign and technical organizational decisions at all levels.

- Synchronization of internal changes and external offers of administrative services.

- Formulation of an information policy and definition of rules for access to and use of electronic services by citizens and businesses.

- Use of modern information and communication technologies. A distinction must be made between "must haves" and "nice to haves" for all standards, whether technical, ethical, legal, or organizational, to establish priorities for implementation .

\section{Implementation process}

Erkollar and Oberer (2008) developed an implementation concept for the benefit of all those responsible for government communication and global branding issues within administrations, including organizational, technical, and legal aspects. The guide can be seen as a metamodel for implementing globally branded e-government strategies and must be adjusted to specific circumstances. Attention is focused on the consideration of administrative targets, the evaluation of critically important criteria for governmental online services, and the needs of global communication and global branding. The underlying e-government process is a dynamic one, with ongoing organizational and technical changes and adjustments. Factors of special interest which may trigger adjustments are changes in the legal conditions for service provision, development of demand for a service, new platforms, and IT security issues. All actions must be overseen by a successfully implemented project management structure. Legal requirements are Legislative acts and international agreements should be issued as needed for protection of the coat of arms and other government intellectual property. Creation of the required organizational framework is recommended for government planning and implementation activities in the area of global communication and branding. An office for global communication and branding should be established. The mission of this office should be to coordinate all government information programs to ensure consistency in the messages that will promote the interests of the country abroad, build support for and among coalition partners within the country, prevent misunderstandings, and inform international audiences. The national coat of arms is the most important visual symbol of a country. It is one of the keys to social cohesion and defines all spheres of a country's communication with its stakeholders. With a uniform national coat of arms, the government and its staff from all departments, divisions, and entities can present a consistent corporate identity to the public. The national coat of arms can be presented visually and verbally across all spheres of government activities and stakeholder communications. The national coat of arms can be visually displayed on the seal, on the national coinage, on government forms, for brand identification, and through electronic media such as the Internet and intranets. When defining where to use the national coat of arms, its specific placement must also be defined. The size of the national coat of arms varies according to the platform on which it is used. Therefore, the symbol should be provided to all government authorities who can use it in a base size or adapt it proportionally. Because it is commonly known that colors have an impact on people's moods and perceptions, the color of the national coat of arms must be used strategically to differentiate it from other symbols and to position the brand of "government" for communication purposes.

Color combinations can include full color, single color, black and white, black 
outline on white, and watermark. Generally, consideration must be given to the meanings of colors in different countries (e.g., in China everything "has to be" red, in France blue and white are common) and the type of writing (e.g., in Europe left to right, in Arabic-speaking countries right to left, in China from top to bottom) in establishing suitably branded e-government structures.

It should also be defined how the symbol is not allowed to be used, e.g., with shadows, with different fonts, in poorquality copies, or rotated or overlapped by other visual objects.

After the construction of the national coat of arms, the presidential seal, the presidential consort seal, and the seal of the country have to be designed and their uses defined and communicated.

To identify the presidency, ministers, ministries, deputy ministers, ambassadors, and diplomatic missions, different presentations of the national coat of arms must be defined, e.g., printing in full color for the presidency, or presenting major items of the symbol backed with gold and the rest of the coat of arms in full color. These different versions of the coat of arms and their meanings must be effectively communicated. National departments should be allowed to distinguish themselves from each other using color. The main color options among which the departments are allowed to choose must be defined. Each department may select one version, but is not allowed to change its selection afterwards. Backing options should not be allowed for departments. Generally, departments should be allowed to choose between full color and a single color. The size of the national coat of arms as well as font types and font sizes have to be predefined, and departments should not be allowed to modify the symbol, to add other objects to it, or to make any other kind of modification. If there are different official languages in the country, language options must be defined for the government brand, e.g., main language only, main language plus one further language in combinations where the primary descriptor always has to be in the main language. These options must be defined both for the whole government and for local ones, e.g., which languages to use for the Swiss government and which for local authorities in the different cantons (same language structure in Geneva, Tessin, and Schwyz?) or how to design branding strategies for language use throughout Turkey or India. Which option a department selects depends on its purpose and the target audience as well. The regulations for the national coat of arms should also define how the symbol is not allowed to be used.

The branding architecture is the organizational structure for the relationship between the main brand and its subsidiary brands. For countries, the main brand is the governmental one, identified by the national coat of arms, and the subsidiary brands are those of the various entities through which the government communicates with its stakeholders.

Branded entities can be classified by levels:

level 1 entities, level 2 entities, level 3 entities.

The national coat of arms is the principal identity of all level 1 entities within a government structure. A structure for a hierarchical branding identity has to be developed and should guide all applications of the national coat of arms. These applications should be different for the three types of government entities.

All level 1 entities (e.g., state, president, ministers, ministries) use only the national coat of arms, with no exceptions. Level 2 entities such as ancillary programs use their own identities certified by the national coat of arms. Level 3 entities (e.g., local authorities) use their own coats of arms or their own identities (e.g., constitutional institutions). 
To manage the branding behavior of entities at all levels of government, various principles must be defined and considered, such as responsibilities for endorsements or placement of the national coat of arms depending on the branding level and in some cases the branding partner. Signage is one of the most visible forms of communication by governments. Branded signs should be used in various areas for internal and external communication. All signs should carry the national coat of arms. Paradeiser (2006) mentioned that branded signs should be designed for the following purposes:

- Identification signs,

- Information signs,

- Emergency and directional signs,

- Promotional signs

- Corporate clothing

Bartelheimer (2009) mentioned that egovernment initiatives, such as Web 2.0 technologies (e.g., blogs) and short message service (SMS) applications, can serve to promote improvements in government services, as can traditional communication tools like community radio call-in shows and local television. Community media can stimulate two-way communication between civil society and the state. Blog environments, with their own communication approaches and techniques, are fundamental to the effectiveness of efforts to improve governance and direct accountability. Using these methods, it is possible to address the stakeholders of governments and their authorities as well as other governments around the world, providing (e.g., in cooperation with other governments or institutions) a platform for exploring global interactions among public opinion, governance, and the public sphere. These new technologies can support the development of a global community with members who want to improve governance and accountability in their home countries. National governments can provide information, communication, and interaction possibilities for people, organizations, foreign nationals, and foreign nations. A globally branded communication infrastructure should be designed and implemented for the government, its embassies, and its consultants around the world. Governments should aim to find a single provider for the required communication infrastructure.

To support data communication needs, providers should be chosen who are able to provide sufficient services, for example an international IP VPN solution. Key factors in the selection of a provider should include global network coverage, quality of service, high level of security, local support, a competitive service level agreement, and cost-effectiveness. Governments should choose experienced global providers of communication services for government organizations, foreign ministries, and government offices to satisfy their needs. Media applications should be used to communicate the message of the government and to enhance high-quality communication with its stakeholders. The strategies used should be differentiated between print and electronic media. In the area of print media, there should be defined guidelines for the presidential seal, the presidency, ministers, ministries, and departments. For electronic media, there should be defined guidelines for email signatures, web sites, presentations, television, video, and CD covers. Rules must also be defined for co-branding.

Level 1 co-branding means that the government is the main sponsor. In this case, the national coat of arms should always have a priority position (e.g., the level 1 branding partner emblem should not be more than three-quarters the size of the national coat of arms). Clear rules must also be defined for how to place the national coat of arms. Figure 1 shows an example of level 1 co-branding. Level 2 co-branding applies to entities with permission of the legislature and to ancillary programs. The national coat of arms should not be less then threequarters the size of the level 2 branding partner emblem. Figure 2 shows an example of level 2 co-branding. 


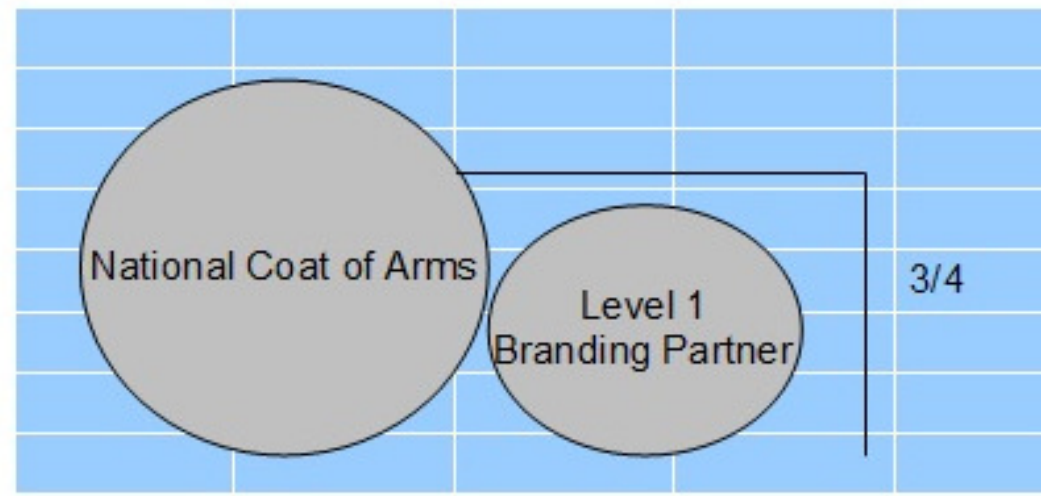

Fig 1. Level 1 Co-Branding

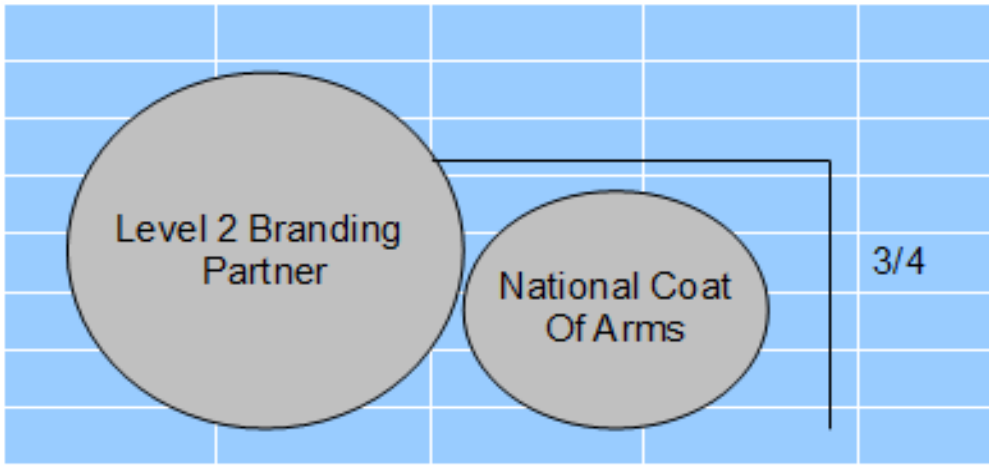

Fig 2. Level 2 Co-Branding

If the branding partner is a lead sponsor, this is level 3 co-branding. The national coat of arms should always be equal to or not less than (for example) three-quarters the size of the partner's emblem. Figure 3 shows an example of level 3 co-branding. For special projects, who is responsible for them, who has to give permission for all branding and communication activities, and which rules have to be followed must all be defined. The same procedure applies in the cases of multiple-partner branding issues and departmental co-branding. Branding rules have to be communicated, and every organizational entity has to know whom to ask in case of uncertainty or special requirements. 

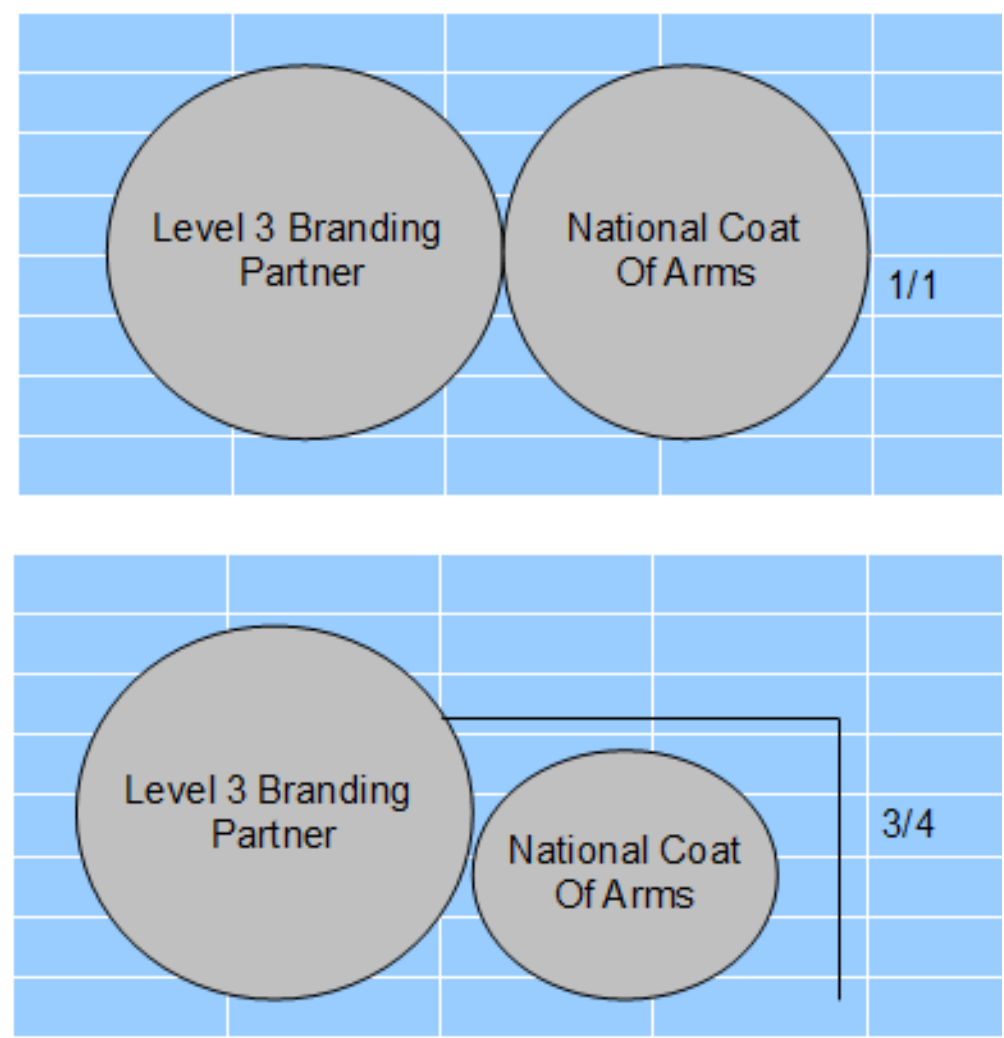

Fig 3. Level 3 co-branding

In general, a structure needs to be developed for the creation of all documents provided to the government's stakeholders (e.g., every document is separately provided or will be generated on demand).

\section{Summary}

Every government department is facing growing pressures to communicate more openly and effectively. A global branding strategy for electronic government services is one approach which is enabling governments to do this. To establish globally branded electronic services, the government must define its brand, the national coat of arms, and a structure which clarifies to all government departments and authorities their rights and duties regarding the global brand. An organizational process must also be created for designing and implementing global branding strategies and for establishing control structures. Governments must decide on the scale and characteristics of their brand. Moreover, technical challenges must be considered, and a provider for the whole set of global communication activities must be selected and evaluated. To implement and operate the globally branded communication structure, a legal framework must be developed and communicated. Rules need to be established for branding and co-branding and structures for internal and external communication developed. A clean and confident visual language which works across a wide range of services has to be developed. A uniform national coat of arms enables the government and its authorities to project a consistent and coherent brand to its stakeholders. 


\section{References}
Bartelheimer,
G.
'Technologiemanagement', IJCU , 14 (2), 12-22.

Erkollar, A. and Oberer, B. (2008), 'How to implement global E-Government strategies', ICC , 2 (3), 122-125.

Erkollar, A (2008) Governmental governance, a structure analysis, Vienna.

Erkollar, A. and Oberer, B. (2003) 'Structure Analysis for E-Government Applications', Portland International Conference on Management of Engineering and Technology (Picmet), Technology Management for Reshaping the World, 20-24 July 2003, Portland, USA.

Erkollar, A. and Oberer, B. (2004), Future Trends of Electronic Government, Orlando.

Huntington, M. (2007) Governmental Branding. How effectiveness and efficiency can be measured, New York. Lakeworth, S. (2008) How important is branding to your marketing strategy? Boston.

Melicher, M. (2007), Communication in enterprises and governments, Vienna.

Oberer, B. (2008),The ethics of governmental communication. A case study, Klagenfurt.

Oberer, B. (2002),Classification portfolio for Electronic Government Approaches, Vienna. 